\title{
Sustainable modernization method to increase energy performance of the public buildings using BIM techniques
}

\author{
Jovita Starynina*, Leonas Ustinovičius, Mantas Vaišnoras \\ Faculty of Civil Engineering, Departament of Construction Management and Real Estate, \\ Vilnius Gediminas Technical University, Vilnius, Lithuania
}

\begin{abstract}
This research represents sustainable building modernization model, which creates knowledge-based decision-making method for old public buildings refurbishment seeking to reach the best energy performance during the design stage. Despite the fast development and spreading standards, challenging research opportunities arise from process automation and BIM adaptation for existing buildings' requirements. To aid decision-making, building simulation is widely used in the late design stages, but its application is still limited in the early stages in which design decisions have a major impact on final building performance. Building design is a multi-collaborator discipline, where architects influence design decisions, engineers, contractors, and building owners. Using digital systems and simulations this modernization method performs already expected building energy consumption in a quickest and economic way. This model is BIM-based where design and refurbishment are based on pre-built indicators, which allows assessing the building energy demand and eco-building parameters.
\end{abstract}

Keywords: sustainable, energy, BIM, decision making.

\section{Introduction}

Buildings have a major impact on the health and well-being of people and the environment. Old buildings use resources, form waste and are expensive to maintain and operate. Achieving to have zero waste buildings are a practice of building design, construction and operation to increase productivity and decrease energy consumption, to use less resources, to reduce the amount of waste and the negative impact on the environment, and to reduce costs during the life cycle. The Energy Roadmap 2050 and 2030 European Energy strongly requires focus more on the energy efficiency on housing sector due to the reason that it is the largest consumer of energy in Europe, accounting for nearly $40 \%$ of the total consumption (European Comission, 2011, 2014; European Parliamant, 2010).

Nowadays sustainability in real estate is very crucial topic and it is very important to mention that energy performance of buildings got a lot attention for last decades (Galle, Vandenbroucke, \& De Temmerman, 2015). Due to buildings' negative impact to environment for which is responsible construction industry, demand on sustainable buildings is increasing (Carvalho, Bragança, \& Mateus, 2019; Jensen, Maslesa, Berg, \& Thuesen, 2018).

The design of buildings with reduced energy use is often accomplished by predicting the energy performance of buildings (Hemsath \& Bandhosseini, 2017). Information exchange between the energy modelling of buildings and their design has many problems, including defects in the parameters of object information, geometric false images, and the confusion of re-entry data (Guzman Garcia \& Zhu, 2015). The main problem of old building modernization is that it must be preceded by documentation review and their information analysis, including different stages of lifecycle involving as well architects, constructors, users and administrators (Linderoth, 2010). And it takes a lot time and effort to evaluate existing situation.

The aim of this research was to create the energy inverse task model of the BIM based design tool and test it on a real public building for modernization purposes seeking to achieve required energy class. This model is based on stakeholders' expectations and includes indicators for comprehensive assessment of buildings' condition, energy efficiency, environmental impacts, modernization cost and duration. This model identifies the automatization potential for data exchange within separate components inside the created tool. Modernization model includes the algorithm for energy analysis and algorithm for optimization of alternative refurbishment measures.

Incorporation of computational methods like aerial photography and laser scanning in architecture makes building performance analysis possible at the early stage of design. Viewing the building as a system and revealing complex

*Corresponding author. E-mail: jovita.starynina@vgtu.lt

(C) 2019 Authors. Published by VGTU Press. This is an open-access article distributed under the terms of the Creative Commons Attribution (http://creativecommons.org/licenses/by/4.0/) License, which permits unrestricted use, distribution, and reproduction in any medium, provided the original author and source are credited. 
dependencies makes possible new approaches and, in order to reach the energy goals with economic efficiency, the use of simulation tools at early stage of design is very important. To reduce efforts to convert data into digital objects, in this research we are using a 3D photogrammetry model. This innovative technique creates an accurate model of a real building in a relatively short period with a small amount of work. This 3D photogrammetry model has precise accuracy for pre-design use case. This model helps to collect data of external building parameters and is usable for design and simulations of energy performance. In many ways, 3D digital model forms a solid foundation for the overall improvement of information management on project implementation and life-cycle asset management. The 3D geometry of the building should be as accurate as possible, the more realistic the model is, the more exact the results we can get (Laguela, Diaz-Vilarino, Martinez, \& Armesto, 2013).

\section{Determining the key energy indicators of a building construction}

At the beginning of the work, it is necessary to determine the basic energy parameters of the building of the analytical building of the partition structures and engineering systems. For this purpose, developed energy class determination of the building (inverse task) is created (Figure 1).

One of the main components of knowledge-based management system is optimization subsystem that will include the tools for pre-selection of alternatives and for decision-making on conceptual stage and after energy analysis of augmented model. The logic of the inverse problem algorithm for pre-selection of alternatives will be developed on conceptual stage. Variations of construction and engineering systems must be identified that are corresponding to the energy performance class, which was determined at the beginning of the variations indication of the chosen to modernize building.

This is innovative concept for a systemic approach to building modernization, which also integrates the costeffective technologies and eco-efficient materials, in order to reduce heat losses, energy consumption and environmental impacts, while increasing the share of renewable energy in buildings.

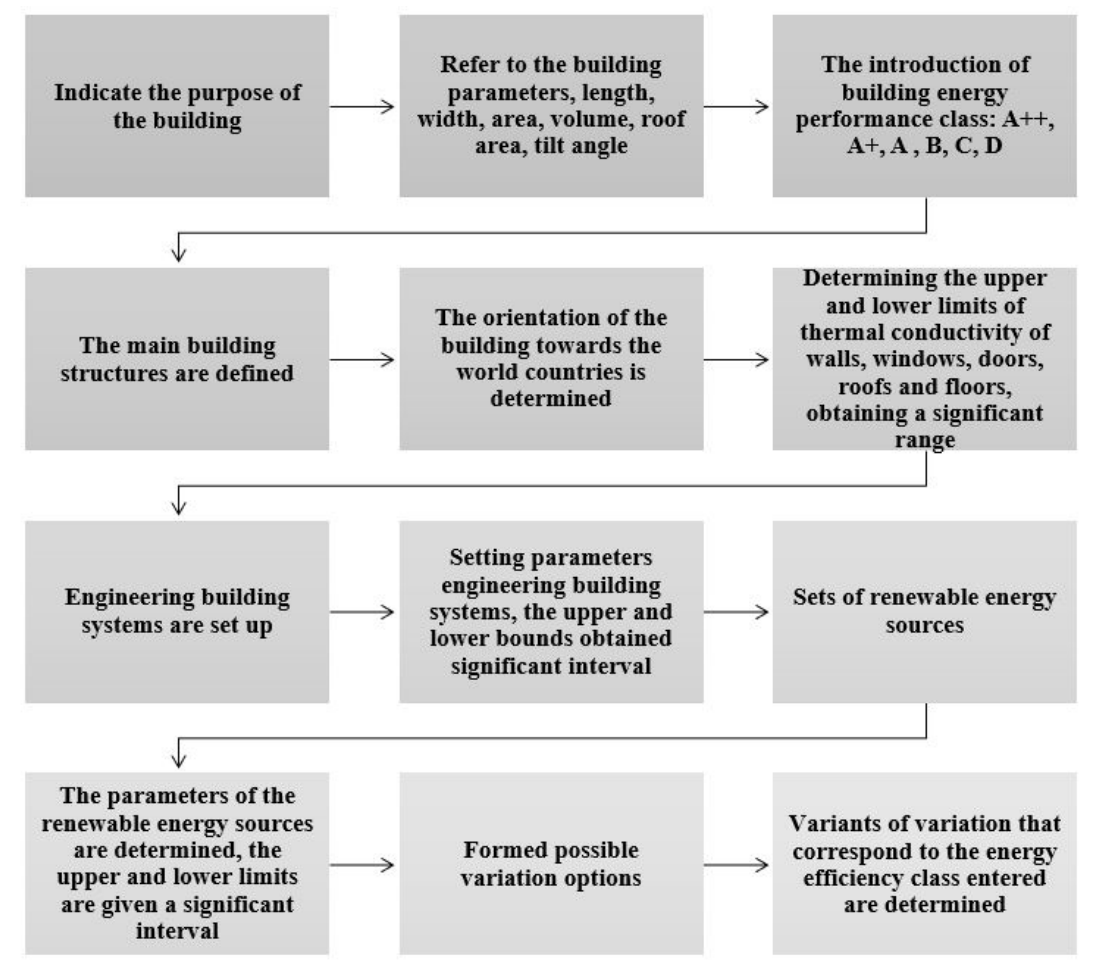

Figure 1. Inverse model for modernization task

\section{BIM use for sustainable public building modernization}

The future technology (BIM) of the constructions (Harris, 2013) would help to solve the high costs, terms of construction process, life cycle and design model reconstructing public buildings of chosen alternative construction issues. It is a new industry term referring to parametric 3D visualization technology and processes in the industry (Taylor \& Bernstein, 2009; Popov, Juocevicius, Migilinskas, Ustinovichius, \& Mikalauskas, 2010). BIM is one of the most promising recent developments in construction industry (Azhar, 2011) BIM includes more of life cycle phases, integrates program controls and standardizes information management so that meanings are clear and consistent 
(Talapov, (2011). Created model of reality is a digital twin of information database, storing all the architectural designs with geometric information and the corresponding technical information of all work (Ding, Zhou, Luo, \& Wu, 2012).

The new approach introduced by the BIM model creates an intelligent decision-making environment for renewal strategies and quality control, while creating the potential to bridge the gap between expected and actual energy efficiency. Separate BIM based models interact within integrated Model Based Engineering System on base of numerical simulation and virtual imitation to generate and evaluate sustainable solutions (Wong \& Kuan, 2014). Building Information Model with integrated new BIM subsystem enables BIM subsystems within BIM-based design tool can be linked to the databases with established sets of library elements describing solutions of modernization measures corresponding to local climate conditions, energy management, life-cycle assessment and database of information connected to one automated simulation system (Figure 2).

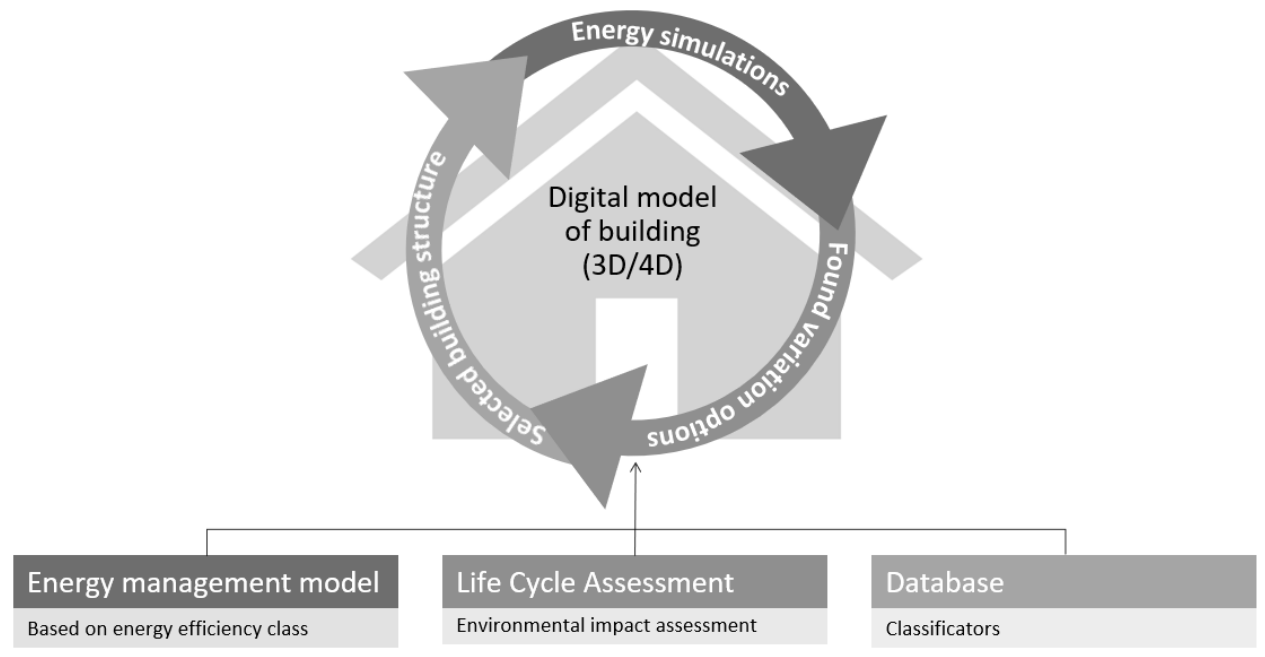

Figure 2. BIM automated system

For better choose and more accurate selection of materials, after calculation of energy class for the modernization of materials, experts select possible alternative measures for modernization, taking into account the result of building energy audit, state of building structures and specific problems found in exact building. Experts, together with building managers, determine criteria set for analysis of alternative modernization measures. Next, experts set values and weights of criteria using pairwise comparison. Formation of alternative combinations of modernization measures was made by using decision tree model.

Decision-making is the process of defining the goals, determining possible alternatives, gathering information about relevant criteria and selecting the optimal alternatives. Optional selected heating type is being selected for each building part alternative by identifying the construction type materials, specifying their technical data.

The active BIM will be further used in simulations of the building behavior, especially for such parameters as temperature inside or the generally understood comfort, depending on external factors (air temperature, rain or wind) and internal ones (number of people, type of activities) (Dong, O’Neill, \& Li, 2014). BIM technologies offer the computational platforms to achieve transition between big data, information technology use and integrated project delivery (Eleftheriadis et al., 2018).

\section{Results}

The aim of this research was to present the inverse task model for selection of optimal combinations of public building modernization and to implement it in BIM technique for sustainable life cycle approach.

Having digital twin of real building allows having lifecycle maintenance of energy consumption, as it allows connecting different systems to one information portal, which can be "living" digital decision-making model. Decisionmaking is the process of defining the goals, determining possible alternatives, gathering information about relevant criteria and selecting the optimal alternatives. Described approach improves not only building sustainability but also leads to the reduction of impacts to environment.

Proposed sustainable energy performance modernization model should further be tested on existing buildings through the modernization process. 


\section{Conclusions}

Building modernization with invers task energy model and BIM technologies have a huge influence on the sustainable building through life cycle performance, since the application of a BIM-based energy management model in the early stages of the building life cycle will ensure the selection of the most energy efficient solutions.

The creation of an optimization system of a pre-built model and the use of BIM-based techniques with simulations and database information allows comparing and selecting the most energy efficient and environmentally friendly solutions for building modernization project. Furthermore, this type of modernization solution can be applied not only to old public buildings, which are needed to be modernized, but also to for new sustainable energy efficiency building construction projects.

A digital twin reality model of building gives the preconditions to create the procedures for a smart modernization process (audits, design/construction process, quality control). The need for such knowledge and practice, especially for integrated building improvement solutions, is of keen importance, as a very large proportion of the buildings in Europe are old and do not comply with energy performance requirements, and this sector has a huge energy saving potential.

\section{References}

Azhar, S. (2011). Building Information Modeling (BIM): trends, benefits, risks, and challenges for the AEC industry. Leadership and Management in Engineering, 11(3), 241-252. https://doi.org/10.1061/(ASCE)LM.1943-5630.0000127

Carvalho, J. P., Bragança, L., \& Mateus, R. (2019). Optimising building sustainability assessment using BIM. Automation in Construction, 102, 170-182. https://doi.org/10.1016/j.autcon.2019.02.021

Ding, L. Y., Zhou, Y., Luo, H. B., \& Wu, X. G. (2012). Using nD technology to develop an integrated construction management system for city rail transit construction. Automation in Construction, 21(7), 64-73. https://doi.org/10.1016/j.autcon.2011.05.013

Dong, B., O'Neill, Z., \& Li, Z. (2014). A BIM-enabled information infrastructure for building energy Fault Detection and Diagnostics. Automation in Construction, 44, 197-211. https://doi.org/10.1016/j.autcon.2014.04.007

Eleftheriadis, S., Duffour, P., Greening, P., James, J., Stephenson, B., \& Mumovic, D. (2018). Investigating relationships between cost and $\mathrm{CO}_{2}$ emissions in reinforced concrete structures using a BIM-based design optimisation approach. Energy \& Buildings, 166, 330-346. https://doi.org/10.1016/j.enbuild.2018.01.059

European Comission. (2011). Energy Roadmap 2050. COM, 885 Final.

European Comission. (2014). A policy framework for climate and energy in the period from 2020 up to 2030. COM, 16 Final.

European Parliamant. (2010). Directive 2010/31/EU of the European Parliamant and of the Council of 19 May 2010 on the energy performance of buildings. Official Journal of the European Union, EPBD2010/31/EU.

Galle, W., Vandenbroucke, M., \& De Temmerman, N. (2015). Life cycle costing as an early stage feasibility analysis: The adaptable transformation of Willy Van Der Meeren's student residences. In $8^{\text {th }}$ Nordic Conference on Construction Economics and Organization, Procedia Economics and Finance, 21, 14-22. https://doi.org/10.1016/S2212-5671(15)00145-8

Guzman Garcia, E. \& Zhu, Z. (2015). Interoperability from building design to building energy modeling. Journal of Building Engineering, 1, 33-41. https://doi.org/10.1016/j.jobe.2015.03.001

Harris, J. (2013). Integration of BIM and business strategy. Masters of Project Management Program. Department of Civil and Environmental Engineering, McCormick School of Engineering and Applied Science, Northwestern University, Evanston, IL. $35 \mathrm{p}$.

Hemsath, T. L., \& Bandhosseini, K. A. (2017). Energy modeling in architectural design. Taylor \& Francis, New York, USA. https://doi.org/10.4324/9781315712901

Jensen, P. A., Maslesa, E., Berg, J. B., \& Thuesen, Ch. (2018). 10 questions concerning sustainable building renovation. Building and Environment, 143, 130-137. https://doi.org/10.1016/j.buildenv.2018.06.051

Laguela, S., Diaz-Vilarino, L., Martinez, J. \& Armesto, J. (2013). Automatic thermographic and RGB texture of as-built BIM for energy rehabilitation purposes. Automation in Construction, 31, 230-240. https://doi.org/10.1016/j.autcon.2012.12.013

Linderoth, H. (2010). Understanding adoption and use of BIM as the creation of actor networks. Automation in Construction, 19(1), 66-72. https://doi.org/10.1016/j.autcon.2009.09.003

Popov, V., Juocevicius, V., Migilinskas, D., Ustinovichius, L., \& Mikalauskas, S. (2010). The use of a virtual building design and construction model for developing an effective project concept in 5D environment. Automation in Construction, 19, 357-367. https://doi.org/10.1016/j.autcon.2009.12.005

Talapov, V. V. (2011). Osnovy BIM: vvedenie v informatsionnoe modelirovanie zdaniy. Moskva: DMK Press. $392 \mathrm{s.}$

Taylor, J. E., \& Bernstein, P. G. (2009). Paradigm trajectories of building information modeling practice in project networks. Journal of Management in Engineering, 25(2), 69-76. https://doi.org/10.1061/(ASCE)0742-597X(2009)25:2(69)

Wong, J. K.-W., \& Kuan, K.-L. (2014). Implementing 'BEAM Plus' for BIM-based sustainability analysis. Automation in Construction, 44, 163-175. https://doi.org/10.1016/j.autcon.2014.04.003 